\title{
UM NOVO POSSÍVEL PELA VIA DA EDUCAÇÃO POPULAR NA FORMAÇÃO CONTINUADA DE PROFESSORES DA EDUCAÇÃO DE JOVENS E ADULTOS
}

\author{
A "NEW POSSIBLE" THROUGH POPULAR EDUCATION \\ IN THE CONTINUOUS TRAINING \\ OF YOUTH AND ADULT EDUCATION TEACHERS
}

\author{
Eduardo Jorge Lopes da Silva ${ }^{1}$ \\ Adriana Bastos Oliveira ${ }^{2}$
}

\begin{abstract}
RESUMO
O presente artigo, recorte de pesquisa desenvolvida em nível de mestrado, busca refletir sobre a viabilidade de construção de uma escola pública, dentro dos princípios da Educação Popular, tendo como norte a formação continuada ofertada aos professores da Educação de Jovens e Adultos (EJA), no espaço da própria escola, no município de João Pessoa, Paraíba. Foram realizadas oito entrevistas com professores e análise documental, a partir de uma pesquisa-ação. Os docentes revelaram uma percepção teórico-empírica abrangente sobre a Educação Popular e que nenhum dos professores buscou curso de formação continuada voltado para EJA por iniciativa pessoal. Concluímos que a Educação Popular está dentro da escola pública porque os sujeitos que lá estão com suas experiências, suas histórias, suas aprendizagens e suas práticas revelam que eles/elas também se sentem/se veem como sujeitos populares.
\end{abstract}

Palavras-chave: Educação popular; Escola pública; EJA; Professores; Formação continuada.

\begin{abstract}
This article, part of research developed at the master's level, seeks to reflect on the feasibility of building a public school, based on the principles of Popular Education, with the continuing education offered to teachers of Youth and Adult Education (EJA) as a guide, in the space of the school in the city of João Pessoa, Paraiba. Interviews were implemented with eight teachers who participated in the continued training process, and documents were analyzed based on action research. The teachers revealed a comprehensive theoreticalempirical perception about Popular Education. As for training, it was found that, by personal choice, none of the teachers sought a continuing education course aimed at EJA. We concluded that Popular Education is with in the public school because the participating educators' experiences, stories, learning, and practices reveal that they also feel/see themselves as popular subjects.
\end{abstract}

Keywords: Popular education. Public school. EJA. Teachers. Continuing education.

\footnotetext{
${ }^{1}$ Atualmente é Professor no Centro de Educação, Departamento de Fundamentação da Educação e no Programa de Pós-Graduação em Educação da Universidade Federal da Paraíba. Doutor em Educação pela Universidade Federal de Pernambuco. e-mail: eduardojorgels@gmail.com

${ }^{2}$ Atualmente é gestora na Escola Municipal de Ensino Fundamental Damásio Barbosa da Franca. Mestra em Educação pela Universidade Federal da Paraíba. e-mail: adipsic@gmail.com
} 


\section{Revista \\ Debates Insubmissos}

\section{INTRODUÇÃO}

Vale (2001) em seu estudo sobre a viabilidade da Educação Popular na Escola Pública, enfatiza que muitas das conquistas educacionais obtidas em favor dos menos favorecidos na nossa sociedade foram frutos das lutas das camadas populares, do seu empenho e de suas formas de articulações.

A autora deixa claro que se faz fundamental tomarmos consciência das condições que se apresentam adversas a uma prática de educação popular na escola pública, para que assim possamos ultrapassá-los. Dentre tantos limites Vale (2001, p. 66-71) destaca: 1. A administração da escola, com as questões estruturais e burocráticas; 2. A infraestrutura da sociedade, que sejam as condições sociais, econômicas, políticas, que ferem os direitos dos cidadãos; 3. A própria formação do educador, a sua prática política, a sua prática educativa; 4. Os limites da dialética: totalidade, transitoriedade, contradição e mudança qualitativa, que no ato de conhecer, vão ganhando espaço e significado.

Na perspectiva dessa autora, viabilizar o projeto da escola pública popular passa necessariamente pela clareza do educador acerca do tipo de educação que ele precisa ajudar a construir ou que tipo de sociedade se deva buscar, tornando-se um ser capaz de intervir tanto na esfera educacional quanto no campo social. Demonstrando sua "competência", não como ser iluminado, portador de todo o saber, mas como sujeito implicado na recuperação de um conhecimento que já existe para além da escola, capaz de trabalhar esse conhecimento no interior da escola.

Ao tratar da produção desse novo conhecimento, da relação entre o saber popular e o saber erudito, Vale (2001) cita Januzzi (1987) afirmando que esta produção na escola pública deve ser motivada pelo educador, que tem o papel de sistematizar os saberes que o povo traz de modo assistemático. Essa sistematização sugere uma ação efetiva do educador no sentido de alocar o que a ciência sabe, o que a ciência traz de novo para aqueles conhecimentos populares. 


\section{novitat \\ Debates Insubmissos}

O que há, na verdade, é um diálogo entre os saberes, partindo do popular ao saber da ciência. Não que o segundo seja mais que o primeiro, mas numa relação permanente de reconhecimento das influências que um tem para com a produção do outro.

É por meio da relação dialética com a realidade que a possibilidade de criação de uma educação que, em se reconhecendo transitória, move-se numa busca incessante pelo novo saber, "uma nova qualidade de aprender, fundamentada na criticidade, na problematização, no questionamento, condições essenciais a uma ação educativa transformadora" (VALE, 2001, p. 71).

Nesse sentido, reconhecemos que, a escola pública popular e o educador nela atuante, precisam estar alinhados com os seguintes princípios (VALE, 2001):

1. A escola não é mais vista como um corpo isolado, mas como constituinte do movimento histórico-social, sendo palco da dimensão de lutas de classe (ibidem, p. 76);

2. A ação pedagógica desenvolvida nessa escola tem uma função contra hegemônica, implicada com a formação da consciência crítica, com a formação de novos saberes e da nova cultura (ibidem, p. 76);

3. O educador é movido pelo sentimento do amor a causa político-pedagógica, condição primeira de quem deseja comunicar-se, dialogar com os sujeitos populares (ibidem, p. 77);

4. As tradicionais cartilhas, bem como o uso indiscriminado e obrigatório dos livros são substituídas por textos produzidos a partir da vivência do próprio aluno; dando início a produção do conhecimento e superando as tradições conteudistas (p. 80-81);

5. $\mathrm{O}$ ato de conhecer passa a ser um processo dinâmico e dialógico entre o professor e o aluno e a sala de aula deixa de ser um espaço de mera recepção e introjeção de uma cultura dominante (ibidem, p. 81);

6. As ações educativas são reflexas do compromisso com a classe social popular; tudo começa a partir desse compromisso (ibidem, p. 85); 
7. Nessa escola, o processo não é de substituição de um conhecimento por outro, mas de integração entre os saberes favorecendo a leitura do real e a construção contínua de novos conhecimentos (ibidem, p. 86);

8. É um espaço de expansão da criatividade e produção de subjetividades, rompendo com os temas padrões e dando lugar aos temas significativos (ibidem, p. 87);

9. Apesar de não negar o conhecimento formal dos currículos escolares, essa escola propõe a construção de um currículo que mantem uma relação direta com a história de vida daqueles a quem ela se destina (ibidem, p. 89);

10. As ações partem sempre de um diagnóstico da realidade e se orientam pelos princípios da educação popular; num movimento permanente de repensar a proposta pedagógica, a organização e o currículo escolar, numa perspectiva democrática e emancipadora (ibidem, p. 93);

11. Investe no processo de formação continuada dos professores, pois busca garantir a ampliação do processo participativo nas decisões e ações; o respeito à autonomia da escola e os sujeitos; a valorização da unidade teoria-prática (ibidem, p. 94-95).

Em relação a este último princípio acima citado, temos visto que, a escola pública construída à luz da Educação Popular, tem na formação/reeducação dos educadores o seu horizonte de possibilidades de construção de uma escola em que o sentimento de pertencimento dos sujeitos populares (educandos e educadores) e de deliberação coletiva é a marca maior do êxito de sua proposta tão pedagógica quanto política, no sentido de seu compromisso com a formação de um sujeito intelectualmente comprometido com a emancipação das camadas populares.

Além disso, concordando com Silva (2011, p. 32) ao justificar a relevância de se pesquisar a formação do professor para a EJA, segundo o foco da Educação Popular, ao asseverar é possível “[...] fazer ciência em torno da formação de professores para a EJA [...], especialmente, quando estamos abordando a formação no chão da escola pública, como iniciativa dos profissionais que lá atuam. 


\section{westet

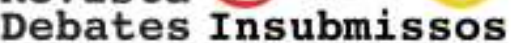

Para Esteban e Tavares (2013), pensar a escola pública na perspectiva do sucesso escolar dos sujeitos na contemporaneidade significa entrar em contato com a dimensão histórica de exclusão da escola pública e da própria sociedade brasileira. E embora a escola para as classes populares tenha uma relevância evidente, o processo de ensino e aprendizagem não acontece de modo satisfatório, como podemos ver ainda hoje, nos altos índices de reprovação, evasão, distorção idade/ano escolar; e dos muitos e muitos projetos de correção de fluxo.

Considerando as análises dos autores, ousamos afirmar que, de fato, a produção do sucesso/êxito escolar dos sujeitos populares não pode ser uma consequência exclusiva das ações de caráter pedagógico, no cotidiano escolar, embora reconheçamos que elas possuem um peso imprescindível. Este resultado escolar precisa ser entendido como fenômeno social que tende ao fracasso, em nossa história brasileira da educação, uma vez que não são consideradas as experiências, os conhecimentos e as demandas das classes populares.

Não há nada que mais contradiga e comprometa a emersão popular do que uma educação que não jogue o educando às experiências do debate e da análise dos problemas e que não lhe propicie condições de verdadeira participação. [...]. De teoria, na verdade, precisamos nós. De teoria que implica numa inserção na realidade, num contato analítico com o existente, para comprová-lo, para vivê-lo plenamente, praticamente. [...]. Nossa educação não é teórica porque lhe falta esse gosto da comprovação, da invenção, da pesquisa. (FREIRE, 1978, p. 93)

A partir desta reflexão de Paulo Freire, podemos então confirmar a ideia de que, nas escolas historicamente construídas no Brasil, e, atualmente, a ação educativa responde a uma determinação, que é a de manter todas as crianças na escola e ampliar o acesso ao ensino superior, contudo sem fraturar o projeto moderno/pós-moderno de sociedade. Assim, o que constatamos no cotidiano é que, o distanciamento entre o modelo de escola e as demandas populares só aumentam.

A escola precisa ser considerada como um espaço privilegiado, que guarda em si as possibilidades de libertação, como espaço que reúne o social em toda a sua complexidade. Nesse ponto, como visto acima em nosso texto, a partir de Vale (2001), também Esteban e Tavares (2013), salientam que as experiências da Educação Popular têm uma significativa contribuição no sentido de oportunizar ao espaço escolar público a formulação de alternativas viáveis e melhor, favoráveis às classes populares. 


\section{noviste

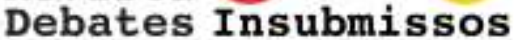

Como alude Spozito (1994) em concordância com Garcia (2003), no cotidiano escolar encontramos a pluralidade e diversidade de acontecimentos que, uma vez postos em foco, se constituem em possibilidades de pesquisas, estudos, projetos do e para coletivo. Possibilitando que este mesmo coletivo afirme o compromisso com o projeto de sucesso individual e coletivo das classes populares, humanizando os humanos a partir das experiências no interior da escola.

Nas palavras de Esteban e Tavares (2013, p. 300, grifos nossos),

[...] investigar o cotidiano da escola pública na perspectiva da Educação Popular implica robustecer o sentido dialógico e de encontro dos sujeitos proposto por Freire na escola, compreendendo o caráter conflituoso inscrito na produção e circulação do conhecimento na esfera escolar [...] o cotidiano escolar integra o processo de formação docente no âmbito da Universidade [e das escolas].

O quadro do sistema escolar público brasileiro só pode ser profundamente compreendido, e porque não dizer, transformado, "se interpretados à luz de um paradigma crítico, complexo, que reconheça os condicionantes histórico-sociais" (ESTEBAN; TAVARES, 2013, p. 301), que vem atravessando os muros da escola pública, enquanto ela se constitui historicamente. O que nos leva a indicar a necessidade, mais uma vez, de um trabalho de formação docente, de modo conectado com as próprias demandas da escola pública. Um processo no qual se problematize, junto ao processo de ensino e aprendizagem, a questão "a que e a quem serve o fracasso escolar da escola pública brasileira?" (Ibidem, p. $301)$.

Compreendemos que é por meio da vivência dos princípios da Educação Popular como elementos de articulação da práxis pedagógica que, poder-se-á transformar o que, até então se configura no slogan, em uma realidade de uma escola pública, de todos, democrática e cheia de sentido para as classes populares. Dentre estes princípios, destacamos, à luz de Esteban e Tavares (2013, p. 303): a) leitura de mundo, recuperando a dimensão política da educação; b) vínculo mais estreito entre a educação e a vida dos educandos; c) desenvolvimento de uma atitude problematizadora, articulando as situações-limites aos inéditos viáveis; d) posicionamento crítico por parte dos docentes e discentes, enquanto uma experiência coletiva e solidária; e) estímulo à autonomia, à participação e à autocrítica; f) e o 


\section{novete \\ Debates Insubmissos}

fortalecimento do diálogo como princípio educativo e meio de produção de relações mais democráticas e colaborativas.

Estes princípios aparecem uma hora ou outra nos diferentes movimentos escolares, no entanto, é primordial dar-lhes maior vigor por meio do processo de formação continuada dos professores, articulando-os a conhecimentos que além de lhes sustentar favorecerão a transformação dos processos educativos.

É nesse sentido que, os autores dizem que "ser importante aprofundar o pensamento 'alternativo de alternativas' sobre as motivações que levam professoras [...] a se encontrarem, por exemplo, fora do horário escolar, muitas vezes aos sábados, para juntas estudarem, horas a fio [...]" (ESTEBAN; TAVARES, 2013, p. 304). Verifica-se, com isso, que estas aprendizagens oportunizam aos professores repensar o seu trabalho escolar levando para sua prática em sala o diálogo, a participação, o coletivo, a alteridade, a solidariedade, as diferenças, as diferentes culturas etc. Oportunizando, ainda, a si e aos educandos experiências mais democráticas, produzindo conhecimentos que notoriamente estão mais voltados à vocação humana de ser mais.

O presente artigo, recorte da dissertação de mestrado ${ }^{3}$ defendida em 2018, tem por objetivo refletir sobre a viabilidade de construção de uma escola pública, dentro dos princípios da Educação Popular para jovens e adultos, tendo como norte a formação continuada de professores da Educação de Jovens e Adultos.

A investigação foi de natureza qualitativa, baseada no ciclo da pesquisa-ação, fundamentada em Thiollent (1986) e Tripp (2005). Foram utilizadas para e geração de dados, técnicas como a observação participante, o diário de campo e a realização de entrevistas semiestruturadas com oito professores de uma escola pública municipal, localizada em um bairro popular do município de João Pessoa, Paraíba. Todos os entrevistados tiveram sua identidade real preservada, por meio de pseudônimo.

\footnotetext{
3 "O Lugar da Educação Popular na Formação Continuada de Professores da EJA: a construção de Novos Possíveis no Chão da Escola Pública", dissertação apresentada ao Programa de Pós-Graduação em Educação, na Universidade Federal da Paraíba.
} 


\section{novitat

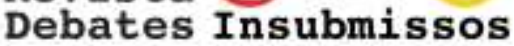

Quanto ao perfil destes profissionais que atuam a EJA da escola campo de pesquisa (Quadro 1) identificamos que a maioria o faz complementando carga horária de outra modalidade de ensino, como os que atuam nos anos finais do Ensino Fundamental, e, em casos mais raros, os dos anos iniciais do Ensino Fundamental, que atua na Educação Infantil. A maioria formou-se pela Universidade Federal da Paraíba, um na Universidade Federal de Pernambuco e uma na Universidade Estadual da Paraíba. Apenas um foi formado por uma instituição da Rede privada de Ensino, ou seja, a maioria dos educadores vem da Rede pública de Ensino Superior.

O professor com maior tempo de atuação está lecionando há 29 anos e o que possui menos tempo de profissão, atua a 1 ano e seis meses. Sendo que, do grupo de participantes os que apresentam maior tempo de experiência na EJA possui 10 anos. A maioria dos participantes está entre 2 ou 3 anos de experiência com este público escolar. O professor mais recente de atuação na escola onde foi realizada a pesquisa, possui sete meses de atuação e a mais antiga 10 anos. Os demais apresentam um tempo/escola bastante diferenciado.

Os professores, em sua grande maioria, são efetivos, ou seja, foram contratados após aprovação em concurso público. Todos tiveram algum tipo de iniciativa de formação continuada, seja em cursos livres para aprimorar a prática profissional ou em cursos de pósgraduação em nível de especialização ou mestrado. Uma participante se destaca dos demais, por apresentar uma sequência de três especializações, sendo todas relacionadas à sua área de formação inicial e a prática como professora ou especialista. Nenhum dos educadores buscou cursos de formação continuada específicos para atuação na EJA e a maioria dos participantes concluiu sua formação inicial entre 2003 e 2009, tendo dois dos participantes concluído em períodos bem distanciados da média do grupo, uma em 1987 e outro em 2012. Por fim, apenas um dos educadores citou que fez seu trabalho de conclusão de curso sobre a EJA e o ensino da Matemática.

Além das entrevistas, foram realizadas análises de materiais como as narrativas, produções escritas dos professores durante os Encontros de Formação Continuada, ofertados no espaço da escola, o Projeto Político Pedagógico e os documentos de orientação pedagógica. As análises dos dados coletados foram realizadas à luz da técnica de Análise de 
Conteúdo, de Laurence Bardin (2011). Vale salientar que a pesquisa foi aprovada pelo Comitê de Ética em Pesquisa do Centro de Ciências da Saúde da Universidade Federal da Paraíba, Parecer $n^{\circ}$ 2.351.457.

Quadro 1 - Perfil dos professores que participaram do ciclo da pesquisa-ação desenvolvida entre fevereiro 2016/ março 2017.

\begin{tabular}{|c|c|c|c|c|c|c|c|c|}
\hline $\begin{array}{c}\text { Nome } \\
\text { Fictício }\end{array}$ & Sexo & Idade & Leciona & $\begin{array}{c}\text { Classe } \\
\text { funcional }\end{array}$ & $\begin{array}{c}\text { Formação } \\
\text { Inicial }\end{array}$ & $\begin{array}{c}\text { Formação } \\
\text { continuada }\end{array}$ & $\begin{array}{c}\text { Tempo } \\
\text { /professor }\end{array}$ & $\begin{array}{c}\text { Tempo/ } \\
\text { EJA }\end{array}$ \\
\hline Davi & M & 34 & Artes/Teatro & Efetivo & $\begin{array}{l}\text { Lic. Ed. } \\
\text { Artística }\end{array}$ & Não consta & 12 anos & 1 anos \\
\hline Lúcia & F & 45 & Cíclo I & Efetiva & $\begin{array}{l}\text { Licenciatura } \\
\text { Pedagogia }\end{array}$ & $\begin{array}{l}\text { Esp. em Gestão } \\
\text { Escolar; } \\
\text { Psicopedagogia; } \\
\text { Ed. Especial }\end{array}$ & 14 anos & 3 anos \\
\hline Roberto & M & 36 & Artes/Música & Efetivo & $\begin{array}{l}\text { Licenciatura } \\
\text { Música }\end{array}$ & Não consta & 03 anos & 2 anos \\
\hline Estela & F & 38 & $\begin{array}{l}\text { História } \\
\text { E. Religioso }\end{array}$ & Prestadora & $\begin{array}{l}\text { Lic. em } \\
\text { História }\end{array}$ & Não consta & 13 anos & 10 anos \\
\hline Madalena & F & 37 & $\begin{array}{l}\text { Língua } \\
\text { Portuguesa }\end{array}$ & Prestadora & $\begin{array}{l}\text { Lic. em } \\
\text { Letras }\end{array}$ & Não consta & 14 anos & 03 anos \\
\hline Joaquim & M & 30 & Matemática & Efetivo & $\begin{array}{l}\text { Lic.em } \\
\text { Matemática }\end{array}$ & $\begin{array}{l}\text { Especialização; } \\
\text { Mestrado em Ed. } \\
\text { Matemática }\end{array}$ & 11 anos & 10 anos \\
\hline Marcos & M & 41 & Matemática & Efetivo & $\begin{array}{l}\text { Licenciado } \\
\text { Ciências }\end{array}$ & $\begin{array}{l}\text { Mestrado } \\
\text { profissional } \\
\text { Matemática }\end{array}$ & 17 anos & 02 anos \\
\hline Cecilia & F & 57 & L. Inglesa & Efetiva & $\begin{array}{l}\text { Lic. em } \\
\text { Letras }\end{array}$ & Não consta & 30 anos & 07 anos \\
\hline
\end{tabular}

Fonte: Informações coletadas na secretaria da escola campo da pesquisa.

$\mathrm{Na}$ sequência, apresentamos as análises interpretativas feitas a partir dos levantamentos das categorias educação popular e formação continuada, promovendo uma costura entre discurso dos entrevistados e o que a literatura nos aponta, formando então nossas primeiras inferências sobre o objeto em tela.

\section{EDUCAÇÃO POPULAR - EDUCAÇÃO QUE CONVERSA COM A VIDA}

Ao proceder às análises temáticas quanto a categoria de Educação Popular, surpreendemo-nos com a quantidade de subtemas surgidos a partir das três questões chaves (concepção de educação popular, relação entre a formação continuada e a educação popular e relação entre a formação continuada da escola e demais ações formativas (Rede de ensino municipal de João Pessoa e outras). Constatou-se a presença de 54 temas no discurso dos 


\section{noviste

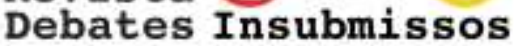

educadores ao tratarem da compreensão sobre Educação Popular, dentre os quais, as subcategorias como educação, reflexão, prática, sujeito popular, relação, ações, diálogo, busca, vida, EJA e aluno estão diretamente relacionadas ao que eles compreendem por Educação Popular. Apesar de demonstrarem certo receio ao responder as questões pertencentes à compreensão que possuem sobre este assunto, os educadores revelaram uma percepção teórica-empírica bem interessante e abrangente acerca da Educação Popular.

Para dar maior visibilidade, ao olhar de cada entrevistado, abaixo listaremos por meio da extração das unidades de contexto mais representativas dessa definição:

É uma educação que vem do povo e volta para o povo. Uma educação que possa fazer com que eles reflitam o meio em que eles estão dentro e como essa educação pode estar ajudando em todas as outras áreas, de trabalho, em relação com a família, enquanto cidadão político.

Davi, professor de Artes/Teatro, em 12/04/2017.

É uma educação que a gente tem que levar em consideração o que a própria comunidade necessita não com imposição.

Lúcia, do Ciclo I/Anos Iniciais do Ensino Fundamental, em 10/05/2017.

Educação popular é aquela que você busca despertar no seu aluno para vida, mas que realmente interessa a ele [...]. Sem deixar os outros conteúdos de lado, mas assim, que ajude a ele no que ele está fazendo na vida, no que ele almeja fazer. De certo modo é levar a educação da escola a conversar com a vida do aluno.

Roberto, professor de Artes/Música, em 10/05/2017.

É uma educação que quer quebrar barreiras [...]. É uma educação que tem o foco no sujeito aprendente [...][...]. É uma educação e uma formação que quer buscar a igualdade.

Estela, professora de História e Ensino Religioso, em 06/05/2017.

Educação popular seria uma educação respeitando a diversidade. Onde na sala de aula você deixa de ser o centro e começa a perceber o aluno como pessoa [...] então a educação popular seria isso valorizar os aspectos de cada aluno como seu.

Joaquim, professor de Matemática, em 13/05/2017.

Educação acessível para todos independente da classe social.

Marcos, professor de Matemática, em 15/05/2017. 


\section{westete

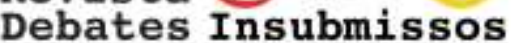

Educação popular deve ser baseada na cultura dos próprios alunos [...]. Não ser aquela coisa erudita, pois no caso dificultaria muito para os alunos entenderem [...]. É olhar para o aluno olho no olho, na mesma altura, nada de salto alto.

Cecília, professora de Língua Inglesa, em 09/06/2017.

As respostas dos educadores nos remetem à discussão sobre à refundamentação da Educação Popular, presente no início dos anos de 1990. Ao adentrar em outros espaços educativos, incorporando outras práticas, a EP teve a necessidade de buscar uma nova linguagem correspondente com esses novos espaços, a escola dentre eles.

Analisamos que os educadores da EJA demonstram em seus discursos ter incorporado à sua práxis pedagógica princípios e métodos da $\mathrm{EP}$, bem como terem construído uma percepção de quem é o sujeito dessa educação.

Como analisa Streck (2006, p. 274),

Por exemplo, uma vez que o projeto pedagógico de uma secretaria de educação assume a educação popular como diretriz, precisa-se prever a incorporação de todos os segmentos da população dentro do discurso. Educação popular, nesse caso, de certa forma volta a ter a conotação de educação pública, de todos. Como encontramos expresso por Martí (2001, p. 375) na segunda metade do século XIX: 'Educação popular não quer dizer exclusivamente educação da classe pobre, mas que todas as classes da nação, que é o mesmo que o povo, sejam bem-educadas'.

Uma das educadoras, Madalena, para responder acerca do conceito de Educação Popular, fez referência a sua práxis como educadora da EJA, tecendo uma crítica ao paradigma tecnicista, colocando, a nosso ver, a EP como prática pedagógica alternativa e mais eficaz para atender as necessidades dos educandos dessa modalidade. Vejamos:

Às vezes no ensino na EJA eu vejo assim, num é para você chegar pegar o conteúdo do livro e aplicar. É você conversar, ouvir seu aluno, saber se ele entendeu aquilo que ele leu [...]. Quando na verdade eles não estão ali querendo a técnica, eles querendo conseguir ler e não ser iludidos, assim enganados. Eles precisam entender aquilo que eles estão lendo. Se ele consegue ler e entender. Num vou dizer que ele vai escrever corretamente, a gente busca né, mas se ele não consegue? Muitos idosos já têm dificuldade, mas se ele entende, ele vai entender História, vai entender Geografia, Matemática. Então a gente tenta buscar esse entendimento deles que flui mais fácil e ai eles têm mais vontade de vir. Do que só a técnica mesmo.

Madalena, professora de Língua Portuguesa, em 11/06/2017. 


\section{novete

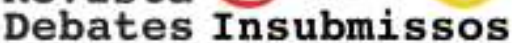

Sabemos que a EJA no Brasil, assim como em diversos lugares no mundo, é fruto merecido das lutas e reivindicações sociais. O povo não recebeu de mãos beijadas o fruto da consciência política dos governantes quanto aos direitos desta população excluída da escola formal em virtude das inúmeras situações de desigualdade social.

Pela luta dos movimentos sociais, do qual Paulo Freire é percussor no campo da alfabetização de adultos, foi que a EJA conquistou seu espaço na escola institucionalizada. Em Política e Educação, Paulo Freire nos esclarece que: "a educação de adultos é melhor percebida quando a situamos hoje como educação popular" (FREIRE, 1995, p. 27), uma vez que com essa denominação seu alcance se estende e agrupa os mais diversos modos de oferta da EJA.

Quando indagamos aos educadores acerca da relação entre a concepção de Educação Popular e a Formação Continuada, os educadores apresentaram visões diferenciadas. Embora a maioria tenha afirmado que há uma relação direta entre essas.

Essa formação tem esse foco no aluno? No que ele realmente precisa. E entende que esse é um espaço em que a escola está tentando levar o professor a entender. Eu acho que é inovador [...]. Sei que eu vou trabalhar, dar aula do assunto, metodicamente, aqueles assuntos que toda disciplina tem que ter. E tem isso! Mas a uma forma é muito diferente. Primeiro: Como é que eu vou fazer isso? É [...] eu ainda estou meio assim, mas acredito que está abrindo minha cabeça, tá chegando [...].

Roberto, professor de Artes/Música, em 10/05/2017.

O conjunto das reflexões apontadas pelos educadores acerca da EP e a Formação Continuada que se vivencia na Escola onde realizamos a pesquisa de mestrado, deu-nos a perceber que foi por meio da metodologia aplicada na formação que os educadores passaram a fazer uma ponte entre a proposta de formação e a concepção de educação popular que costurou todo o processo, avançando em direção ao cotidiano escolar. Scocuglia (2005, p. 84) coloca que,

Ao contrário, a educação estimulada por uma construção curricular problematizadora deve ser coletiva, fundada em perguntas e problemas, entre as quais: O que aprender? Como aprender? Por que aprender? Aprende-se individual ou coletivamente? O conhecimento é neutro? Quem deve escolher conteúdos programáticos, metodologias, comportamentos e procedimentos? O conhecimento dos alunos como parte do currículo é respeitado? Os diálogos de saberes serão 


\section{weste \\ Debates Insubmissos}

validados? E a experimentação? E os livros didáticos: serão prescritivos ou interativos e criativos; normativos e preconceituosos ou democráticos e éticos?

Para os educadores a EP é uma forma de educação que produz a mudança na forma de pensar dos sujeitos educadores e que por meio da formação continuada estavam tendo a possibilidade de mudar a percepção sobre a práxis e sobre as formas de ver/relacionar-se entre os sujeitos populares.

Conforme ilustra as seguintes unidades de contexto recortadas do discurso da educadora Estela (professora de História e Ensino Religioso, em 06/05/2017):

Eu percebo a relação [...]. Eu percebo em mim quando eu mudo o meu olhar sobre os sujeitos, quando eu me preocupo na minha aula de trazer aquele conteúdo e aquela informação. Sim porque bota a gente para refletir, para repensar e para corrigir coisas que talvez não estejam tão bem. Porque talvez naquele momento a gente não estivesse tão focado em quem está do outro lado.

Para esta professora, a formação continuada é potencialmente importante para o educador e para a construção de uma práxis mais significativa para os educandos, uma vez que, pela perspectiva popular trazida, ela instiga ao professor a sair da zona de conforto, do mecânico. O trecho abaixo denota essa compreensão:

\footnotetext{
Eu vejo tanto no meu trabalho quanto dos outros professores é como se fosse uma vitamina de coragem para a gente sair da nossa zona de conforto ou daquilo que já está mecânico e a gente já está acostumado a fazer. Para o desconforto do novo, né de tentar fazer uma coisa diferente ou só de parar de fazer aquilo quando não tiver sentido, então não tem para que fazer.
}

Estela, professora de História e Ensino Religioso, em 06/05/2017.

Considerando o pensamento de Estrela (2006, p. 55), quando afirma que "não basta prescrever a autonomia da escola, o seu papel na comunidade e a cultura colegial dos professores para que tudo se transforme em pouco tempo". Como veremos abaixo com a fala do educador Davi, acerca da dificuldade de mudança da práxis tradicional à práxis na perspectiva progressista, Estrela (Ibidem) esclarece que "Os professores foram, durante dezenas de anos, tratados como funcionários e a sua autonomia, sem dúvida exercida na sala de aula, manifestava-se mais por uma atitude defensiva do que activa no que se refere à escola e à comunidade". 


\section{Revista \\ Debates Insubmissos}

Avaliamos de fundamental importância trazer à luz, a reflexão crítica, feita pelo educador Davi, acerca das limitações de alcance da formação continuada, considerando que a escola é campo de conflito permanente entre as diferentes perspectivas de Educação que cada educador traz consigo.

[...] a proposta de formação na escola tenta, mas por uma formação não popular que a gente teve na formação secundarista e a própria formação universitária não favorecer uma educação popular (...) às vezes tem conflitos, mas há uma tentativa de uma educação popular. Agora como conseguir que ela seja efetivamente popular esse é o segredo, é um mistério devido as nossas formações, enquanto aluno, que nós professores tivemos.

Davi, professor de Artes/Teatro, em 12/04/2017.

Nesse sentido, concordamos com Esteban e Tavares (2013, p. 300), quando elucidam que a investigação do cotidiano escolar, e nesse sentido, também do espaço formativo ofertado na escola, a partir da perspectiva da Educação Popular implica em "robustecer o sentido dialógico e de encontro de sujeitos proposto por Freire na escola, compreendendo o caráter conflituoso inscrito na produção e circulação de conhecimento na esfera escolar".

Ao serem convidados a traçar um paralelo entre a formação continuada que vivenciaram na escola onde atuam como professores e as ações formativas das quais participaram pela Secretaria Municipal de Educação, os educadores estabeleceram uma relação de oposição, acentuando a existência clara de conflitos epistemológicos, metodológicos e de objetivos entre essas práticas formativas. Como nos mostra o seguinte depoimento:

Não tem comparação. Eu vejo como oposto. O que a escola está buscando o que se busca lá. Lá foi uma coisa muito informativa: o que está acontecendo, o que precisa acontecer. Daí eu não sei. Aqui a gente faz caso a caso, pensando diretamente na nossa situação é muito mais proveitoso infinitamente mais proveitoso do que o que foi feito lá.

Roberto, professor de Artes/Música, em 10/05/2017.

Para melhor caracterizar as respostas dos participantes neste ponto da investigação, decidimos por construir o quadro abaixo, estabelecendo a partir da fala dos professores, um contraponto entre as características da Formação construída na Escola campo de pesquisa e as 
demais ações formativas da Rede de Ensino, ofertada pela Secretaria Municipal de Educação da cidade de João Pessoa. Analisemos:

Quadro 2 - Contraponto entre as formações continuadas ofertadas aos professores da EJA pesquisados.

\begin{tabular}{|c|c|}
\hline $\begin{array}{c}\text { Ações de formação continuada } \\
\text { (Rede de ensino e outras instituições) }\end{array}$ & $\begin{array}{l}\text { Formação Continuada à luz da EP } \\
\text { (Escola em estudo) }\end{array}$ \\
\hline 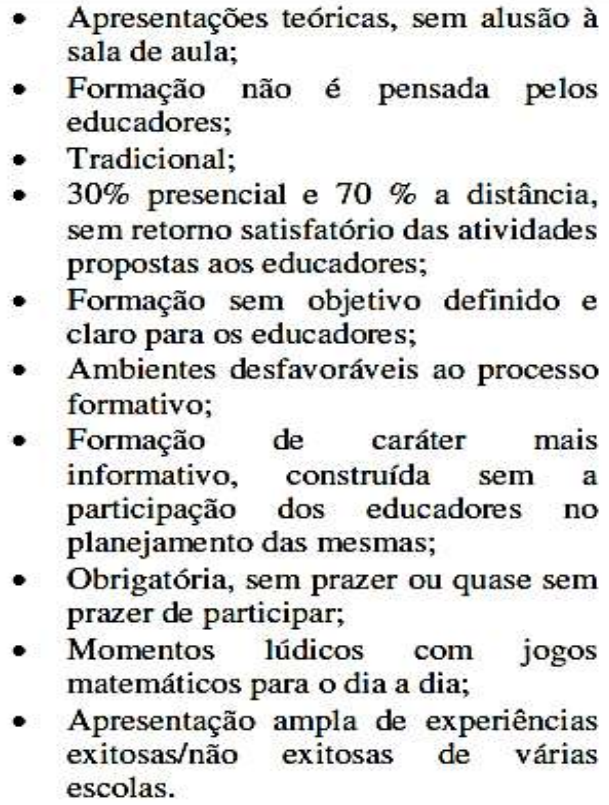 & $\begin{array}{l}\text { - Teoria e prática articuladas às } \\
\text { situações da escola; } \\
\text { - Educadores pensam a formação, } \\
\text { informando suas necessidades; } \\
\text { - Focada na atualidade da sala de aula e } \\
\text { da educação; } \\
\text { - } 100 \% \text { presencial, com atividades } \\
\text { discutidas e repensadas pessoalmente } \\
\text { ou por meios de comunicação } \\
\text { definidos pelo grupo; } \\
\text { - Educadores percebem o objetivo da } \\
\text { proposta e dos encontros; } \\
\text { Formação construída com e para o } \\
\text { coletivo de educadores/as; que produz } \\
\text { "bagagem e não peso"; } \\
\text { Obrigatória, com prazer em participar } \\
\text { apesar do cansaço presente da rotina } \\
\text { de trabalho; } \\
\text { Troca de experiência de sala em todas } \\
\text { as áreas, com foco na atualidade da } \\
\text { educação; } \\
\text { Trabalho centrado nos problemas e } \\
\text { soluções para o dia a dia da escola. }\end{array}$ \\
\hline
\end{tabular}

Foi marcante a posição crítica dos educadores quanto às ações de formação continuada oferecida pela rede de ensino, tanto pelos objetivos não alcançados, quanto pela forma de condução do processo, como podemos constatar na seguinte entrevista:

Eu tenho feito algumas críticas em relação a formação da prefeitura, porque, eu posso até está equivocada, mas eu vejo muito solta. Você tem que ser disciplinado para fazer aquilo ali, você faz as leituras e coloca lá as respostas. Pelo acompanhamento das postagens as pessoas colocam lá o que não faz sentido.

Lúcia, professora do Ciclo I/Anos Iniciais, em 10/05/2017.

Apenas um dos educadores mencionou ter se surpreendido com a formação ofertada pela rede de ensino. Sugerindo em sua expressividade que o ideal seria agregar à formação da escola mais aspectos lúdicos, como jogos na Matemática. Embora tenha demonstrado que a 


\title{
Revista \\ Debates Insubmissos
}

formação da escola, busca ir além da Matemática, dos conteúdos, de uma única área do conhecimento. Ele colocou:

\begin{abstract}
A dinâmica da formação foi bem legal, até me surpreendeu, muita coisa envolvendo jogos matemáticos e isso para gente no dia a dia é enriquecedor. A formação aqui que eu digo de muito legal é essa troca. Porque aí não é só matemática, são as coisas especificas do colégio, que eu acho importante. Essas combinadas entre o grupo e também a questão de você estar mais atualizado na educação mesmo. O que há de novidade na educação, essas coisas assim. A gente aqui tenta trazer isso.
\end{abstract}

Marcos, professor de Matemática, em 15/05/2017.

Ao analisar tanto as críticas feitas às iniciativas de formação da Rede, quanto às críticas sugestivas feitas ao processo continuado de formação para EJA consolidado na Escola, reportamo-nos às reflexões de Maria Aparecida Zanetti, em texto escrito por ocasião do II Seminário de Educação de Jovens e Adultos. A autora afirmou que os processos de formação dos educadores da EJA exigem uma infraestrutura muito diferente daquela que ocorre em uma palestra para um grande número de educadores onde a discussão sobre a prática ocorre de forma genérica.

Para Zanetti (2008, p. 82), “A formação exige maior disponibilidade de tempo de seus formadores, bem como deslocamento para regiões onde estão as escolas para trabalhar com o coletivo". Outrossim, a formação de educadores exige uma reflexão sobre a articulação entre a "singularidade e totalidade no processo de conhecimento vivenciado na escola" (idem, p. 82).

No item seguinte, apresentamos uma reflexão sobre a formação continuada como possiblidade de construção de novos saberes para os professores da EJA.

\section{FORMAÇÃO CONTINUADA - CAMINHO PARA CONSTRUÇÃO DE NOVOS SABERES}

Quanto a esta categoria verificamos o maior número de elementos temáticos no processo de categorização do discurso dos educadores participantes, sendo as mais frequentes: formação, práxis, EJA, Rede, saberes, aprofundamento e estágio. Para sondar os caminhos de formação continuada percorridos até o momento pelos educadores da EJA, os indagamos 


\section{nowitt

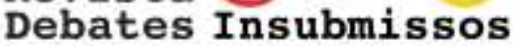

acerca das iniciativas de formação continuada. Todos tiveram algum tipo de iniciativa de curso de formação, após o término da graduação. Como mostrado no Quadro 1, acima neste artigo, os educadores buscaram: especializações na área de Educação, mestrado em Matemática aplicada à prática profissional, mestrado em Educação Matemática, cursos livres para aperfeiçoamento técnico na área de Artes, cursos intitulados de Formação Continuada na área de ensino e curso de formação para atuação em programa federal (Projovem).

Apenas dois professores relataram, diretamente, que tais iniciativas têm como principal fator a práxis pedagógica, no sentido de desenvolvê-la melhor. Uma das participantes se destaca por ter buscado e conseguido concluir três especializações em diferentes áreas de aprofundamento da Educação e ainda cursos de formação continuados relacionados à Educação Especial, hoje chamada, Educação Inclusiva.

Explicando seu entusiasmo, pós-formação inicial, uma das educadoras diz que, para ela, a formação continuada é

Como o próprio nome diz é dar uma continuidade a sua formação. E essa continuidade precisa ser focada naquilo que você está vivenciando. Não uma formação para que você continue vendo aquele conhecimento teórico, mas um conhecimento prático da vivência do dia a dia, na questão da troca de experiências e construção coletiva.

Lúcia, professora do Ciclo I/Anos Iniciais, em 10/05/2017.

Uma fala que nos remeteu à insatisfação histórica dos educadores, que passam a atuar na EJA, com os cursos de formação inicial, em especial às licenciaturas, bem como com as propostas e programas de formação continuada, pois, como assevera criticamente Zanetti (2008, p. 82), “[...] dada a precária abordagem sobre EJA em nossas universidades, os processos de formação continuada nas redes de ensino acabam se vinculando mais à ideia de formação inicial, do ponto de vista da temática, que na perspectiva da formação continuada". Outro elemento que nos chamou a atenção foi quando de maneira, emocionada, alguns educadores relataram ter tido dificuldades para concluir os cursos de pós-graduação. Apontando que o contexto do trabalho como docente não favorece. Uma vez que se sentem, em termos de tempo e condições físico-mentais, completamente tomados pelo exercício da profissão. 


\title{
westet

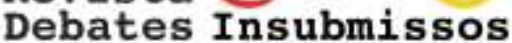

\begin{abstract}
Contudo, se no fordismo/taylorismo o trabalhador era tido como um prolongamento da maquinaria, os capitalistas neoliberais perceberam que os lucros poderiam ser maiores se, além da força de trabalho muscular, explorassem, também, subjetivamente o trabalhador, como um ser pensante que, conscientemente, poderia ser integrado ao processo produtivo. (PAIVA, 2012, p. 30)
\end{abstract}

Outra questão observada e que pode ser considerada complementar, refere-se à formação que os educadores tiveram (ou não), para atuar na modalidade de Educação de Jovens e Adultos. Os dados nos levaram a destacar que, primeiro, nenhum dos professores entrevistados buscou curso de formação continuada voltado para EJA por iniciativa pessoal de formação, como revelam as falas das seguintes educadoras:

Não! Porque eles não pedem uma formação específica de EJA. Para ensinar no ciclo III e IV. Tem que ter a mesma formação que para ensinar no fundamental II.

Madalena, professora de Língua Portuguesa, em 11/06/2017.

É eu lembro, mas não com tanta clareza, mas lembro, assim que quando eu comecei, quando eu recebi essa proposta para trabalhar a noite também. Se falou muito do perfil do professor com relação à EJA. De ter esse perfil, num sei, de conseguir transformar aquele conteúdo que é formal numa coisa que eles entendessem a partir da realidade deles.

Estela, professora de História e Ensino Religioso, em 06/05/2017.

Os educadores alegaram que a Secretaria de Educação não exigia formação específica em EJA, nem inicial, nem continuada, para lecionar para este público. Quando os educadores ingressam na Rede para trabalhar recebem por parte da Secretaria de Educação, através da coordenação da EJA, e dos gestores escolares certa orientação prática, ou seja, há sempre um discurso acerca de como lidar com o público da EJA.

Segundo os educadores relataram que durante a formação inicial o conteúdo da EJA foi trazido numa escala que variou entre o "nada-muito pouco-superficial-ineficaz. Como ilustra a fala do educador Davi sobre a sua licenciatura.

Não, nunca. Passou muito superficial no curso de licenciatura que acaba não sendo no meu ponto de vista eficaz. Eu nem lembro quem foi o professor que deu essa parte de licenciatura. Foi muito superficial.

Davi, professor de Artes/Teatro, em 12/04/2017.

Terceiro, que os professores das licenciaturas não articulavam teoria-prática, quando acontecia de tratarem da EJA e ou acerca da Educação Popular. A educadora Estela reflete sobre esse ponto: 


\section{novete \\ Debates Insubmissos}

[...] Aí eu não lembro especificamente da EJA, mas eu lembro disso, que tinha um discurso, mas que não vinha acompanhando uma prática [...]. Então eu lembro com clareza que a gente fazia uma distinção muito clara dentro do curso. Tinham aqueles professores que somavam que traziam coisas pra gente, que faziam sentido e tinham outros que eram muito desassociados. O que ele falava num tinha muito a ver com a prática. Nem dele, nem com a que a gente queria começar a ter.

Estela, professora de História e Ensino Religioso, em 06/05/2017.

Quarto, os educadores relataram sobre a escassez de espaços formativos específicos para atuação na EJA e que a pouca oferta destes acontecia de forma não direcionada às reais necessidades do educador e de seus educandos. A educadora Lúcia se posiciona,

Como eu estava comentando aquela formação que tem a distância ela não tem direcionamento para EJA. É só para os ciclos de alfabetização que pode ser o os ciclos do PNAIC ou os ciclos da EJA. Então, não é especifico.

Lúcia, professora do Ciclo I/Anos Iniciais, em 10/05/2017.

Quinto, os entrevistados se queixaram do fato de os professores que atuam em mais de uma modalidade, não poderem escolher fazer a formação da EJA, ao invés da formação por disciplina. Ou seja, na percepção dos educadores a prioridade é o conteúdo da disciplina e não o público, o que inviabiliza uma formação interdisciplinar, de fato, tanto para EJA quanto para as demais modalidades de ensino.

Não! Porque até a formação da prefeitura eu não conseguia fazer pela EJA. Eu fazia como professora de Língua Portuguesa. Porque a formação é feita de forma separada.

Madalena, professora de Língua Portuguesa, em 11/06/2017.

Analisando os efeitos dessa escassez de espaço de formação específico para EJA dentro da rede de ensino, uma das educadoras se coloca:

Não, as formações de que participei foram sempre de Inglês para fundamental II. Uma coisa é você dar aula a um adulto ele tem um comportamento assim, por exemplo, um comportamento não aceitável, aí você tem que analisar mil coisas, quem é o adulto? Tem que ter um cuidado, num pode tratar ele do mesmo jeito que trata o adolescente. A gente olha para o aluno e não pode ter a mesma reação, por exemplo, saia da sala. Quer dizer tem todo um olhar diferente. EJA é EJA é um mundo diferente. Para você ver até o ambiente da sala muda.

Cecília, professora de Língua Inglesa, em 09/06/2017.

E sexto, na percepção dos educadores, as contribuições da formação inicial e das ações de formação continuada que haviam participado até o momento trouxeram de 


\title{
nowitt

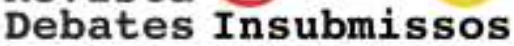

contribuição somente os conhecimentos gerais acerca do ensino. E não sobre o ensino na EJA. Frisam que, embora tenham sido experiência de contato com o outro, estas experiências não se aproximavam o suficiente de como se relacionar, ensinar ao aluno da modalidade em tela.

Contribuiu. Porque você ter o contato com o outro, mesmo não sendo de uma escola específica, sendo de música, são experiências. Mas, mesmo assim, ensinar na EJA é uma coisa nova para mim. De ter um aluno que vai para sala de aula querendo estudar música e outro aluno que está na sala de aula e que você tem um monte de coisa para trabalhar que não é somente música.

Roberto, professor de Artes/Música, em 10/05/2017.

Contrariando a fala dos demais colegas, uma educadora citou que a formação na militância dos movimentos sociais favoreceu a uma compreensão da práxis pedagógica na EJA, como mostra:

\begin{abstract}
Essa conjugação entre teoria e prática sempre esteve presente na minha formação porque foi assim e isso é muito igual para EJA. Não adianta eu estar na sala de aula sem passar para aquele aluno, diante dos olhos dele, a própria experiência dele. Porque tem muita gente que tem costume de olhar quem tem mais experiências de vida, mas não tem o conhecimento formal como uma criatura muito ingênua. Mas de ingênua não tem nada. Tem uma experiência que a gente nem se aproxima. Mas a gente chegar perto daquele aluno e tocar e fazer com que essa experiência transborde dele, aí é a prática de sala de aula. É o desafio que a gente lida.
\end{abstract}

Estela, professora de História e Ensino Religioso, em 06/05/2017.

Em nossa avaliação, a educadora Estela, aborda em seu relato, uma concepção do que vem a ser práxis na EJA, a partir da perspectiva da Educação Popular.

A ausência da abordagem da EJA enquanto modalidade de ensino denota a imensa fragilidade curricular no campo das diversas licenciaturas. Delegando à EJA somente os espaços dos estágios e ou como área de aprofundamento. E como não há concursos públicos específicos para atuação na EJA, muitos professores optam durante a formação inicial por uma área de aprofundamento com mais oportunidades de trabalho/emprego. Fatos que contradizem a Resolução n ${ }^{0}$ 3, de 15 de junho de 2010, que institui as Diretrizes Operacionais da Educação de Jovens e Adultos, definindo no Art. 10 que,

O Sistema Nacional Público de Formação de Professores deverá estabelecer políticas e ações específicas para a formação inicial e continuada de professores de Educação Básica de jovens e adultos, bem como para professores do ensino regular que atuam com adolescentes, cujas idades extrapolam a relação idade-série, desenvolvidas em estreita relação com o Programa Universidade Aberta do Brasil (UAB), com as Universidades Públicas e com os sistemas de ensino. 


\section{Revista \\ Debates Insubmissos}

Observando o que diz a Resolução $\mathrm{n}^{\mathrm{o}} 2$, de $1^{\mathrm{o}}$ de julho de 2015 , que define as Diretrizes Nacionais para a Formação inicial e continuada dos professores da Educação básica em todas as etapas e modalidades de ensino analisamos que há uma distância significativa entre o que preconiza a legislação e as experiências formativas dos educadores da EJA, de modo particular, neste estudo.

Quando os educadores se colocam afirmando que somente por meio da prática é que poderão, pela primeira vez se aproximar, ter um olhar diferenciado para os sujeitos da EJA, formando saberes significativos para práxis pedagógica, fica evidente a deficiência das licenciaturas, quando comparamos ao que prevê a referida resolução, em seu Artigo $3^{\circ}, \S 5^{\circ}$, quando trata dos princípios da Formação de Profissionais do Magistério da Educação Básica. Por exemplo, quando Joaquim, um de nossos educadores entrevistados se coloca afirmando que,

Eu já fiz monografia, pesquisa na EJA (...). O curso de pós foi voltado para educação. Eu estudei as dificuldades encontradas pelos alunos na Vila dos Pescadores. Dificuldades encontradas em Matemática. Aí fiz focando nas dificuldades encontradas em Matemática, não no público em si (...). Acredito que é a prática, o dia a dia, que nos faz ter um olhar diferenciado para o público da gente.

Joaquim, professor de Matemática, em 13/05/2017.

Podemos considerar com um dos fatos mais relevantes da prática da pesquisa, que ora efetivamos, quando o educador Joaquim, respondendo a entrevista, deu-se conta de que no momento em que investigou a aprendizagem/dificuldades dos alunos da Vila dos Pescadores seu olhar voltou-se para o conteúdo da pesquisa e não para o sujeito da pesquisa. Apesar de ser com o público da EJA, ela notou que seu foco foram as dificuldades em Matemática.

\section{CONSIDERAÇÕES FINAIS}

Apesar do distanciamento existente entre a formação continuada ofertada pela rede pública municipal de educação de João Pessoa-PB e a realidade das escolas, dos professores e da Educação de Jovens e Adultos, constatamos que ao se ofertar formação continuada no território específico de cada escola, pode ser um passo ao encontro de uma perspectiva de educação pública, pautada nos princípios da educação popular. 
Nesse sentido, compreendemos que tais princípios são as linhas que possibilitam aos educadores em formação continuada a feitura de novas costuras, o entrelaçamento dos saberes individuais e a confecção de novos entendimentos acerca do sujeito da EJA e de sua práxis pedagógica, numa realidade tão desafiadora como é a das escolas públicas.

Dentro de nossa experiência investigativa, a presença da Educação Popular, como paradigma de orientação e inspiração da proposta de formação continuada dos educadores da EJA, serviu como meio para garantir o caráter democrático e pedagógico de todo o processo. Nesse sentido, pudemos refletir no coletivo, que assim como na formação continuada em processo, na práxis pedagógica, o pedagógico e o político não se separam. E que esta visão é primordial quando tentamos compreender às várias conjunturas, contextos e os sujeitos para então, de modo crítico, poder ensinar.

A Educação Popular encontra-se dentro da Escola Pública porque, entre outras coisas, os sujeitos que lá estão com suas experiências, suas histórias, suas aprendizagens e suas práticas revelam que eles/elas também se sentem/se veem como sujeitos populares. Assim vimos juntos aos educadores participantes. Reconhecer-se como sujeito popular é o primeiro passo para novas práticas, mas não é o último. Muitos seguem com práticas motivadas por outros paradigmas. No entanto, a consciência do fato, não pode ser negada. E esta consciência é uma contribuição de uma formação implicada com a crítica transformadora de mundos e de realidades.

\section{REFERÊNCIAS}

BRASIL. Conselho Nacional de Educação. Diretrizes Curriculares Nacionais para a formação inicial em nível superior (cursos de licenciatura, cursos de formação pedagógica para graduados e cursos de segunda licenciatura) e para a formação continuada. Brasília, Resolução n ${ }^{\circ} 2$, de $1^{\circ}$ de Julho de 2015.

BRASIL. LDB 9394: Diretrizes e Bases da Educação Nacional. Brasília, 1996. 
BRASIL. Conselho Nacional de Educação (CNE). Parecer CNE/CEB n $11 / 2000$. Diretrizes Curriculares nacionais para a Educação de Jovens e Adultos. Brasília, maio, 2000.

ESTEBAN, Maria Teresa; TAVARES, Maria Tereza Goudard. Educação Popular e a Escola Pública: antigas questões e novos horizontes. In: STRECK, Danilo; ESTEBAN, Maria Teresa (Orgs.). Educação Popular: lugar de construção social coletiva. Petrópolis: Vozes, 2013.

ESTRELA, Maria Tereza. A formação contínua entre a teoria e a prática. In: FERREIRA, Naura Syria Carapeto (Org.). Formação Continuada e gestão da educação. 2. ed. São Paulo: Cortez, 2006.

FREIRE, Paulo. Educação como prática de liberdade. Rio de Janeiro: Paz e Terra, 1978.

FREIRE, Paulo. Política e educação. São Paulo: Cortez Editora, 1995.

GARCIA, Regina Leite. Método: pesquisa com o cotidiano. Rio de Janeiro: DP\&A, 2003.

MELITO, Leandro. Falta confiança entre os professores e secretarias de educação. Reportagem da Agência Brasil, publicada em 30/07/2018. Disponível em: http://agenciabrasil.ebc.com.br/educacao/noticia/2018-07/metade-dos-professores-no-paisnaorecomenda-propria-profissao

PAIVA, Lauriana G. de. A formação continuada dos professores como estratégia para Toyotização da educação. In: OLIVEIRA, Daniela Motta de. Formação Continuada de professores: contribuições para o debate. Juiz de Fora: UFJF, 2012.

SCOCUGLIA, Afonso Celso. As reflexões curriculares de Paulo Freire. Revista Lusófona de Educação, 2005, n. 6, p. 81-92.

SILVA, Eduardo Jorge Lopes da. Prática discursiva de formação de professores alfabetizadores de jovens e adultos em uma experiência de educação popular. 2011. Tese (Doutorado em Educação) - Programa de Pós-Graduação em Educação, Universidade Federal de Pernambuco, Recife, 2011.

SPOSITO, Marília. O povo vai à escola: a luta popular pela expansão do ensino público em São Paulo. São Paulo: Loyola, 1994.

STRECK, Danilo R. A educação popular e a re(construção) do público. Há fogo entre as brasas? Revista Brasileira de Educação. ANPED, Associação Nacional de Pós-Graduação e Pesquisa em Educação. Maio/Agosto. 2006, v. 11, n. 32, p. 272-284.

THIOLLENT, Michel. Metodologia da pesquisa-ação. São Paulo: Cortez, 1986.

TRIPP, David. Pesquisa-ação: uma introdução metodológica. São Paulo: Revista Educação e Pesquisa, v. 31, n. 3, p. 443-466, set./dez. 2005. 
VALE, Ana Maria do. Educação Popular na Escola Pública. São Paulo: Cortez, 2001.

ZANETTI, Maria Aparecida. Reflexões sobre a Formação de Educadores de Jovens e Adultos em Redes de Ensino Públicas. In: MACHADO, Maria Margarida. Formação de Educadores de Jovens e Adultos. Brasília: Secad/MEC, UNESCO, 2008.

Submetido: $15 / 06 / 2021$

Aprovado: 22/07/2021 